\title{
Glucocorticoids and endothelial function in inflammatory diseases: focus on rheumatoid arthritis
}

\author{
Frank Verhoeven ${ }^{1,2}$, Clément Prati $^{1,2}$, Katy Maguin-Gaté $^{1}$, Daniel Wendling ${ }^{2,3}$ and Céline Demougeot ${ }^{*}$
}

\begin{abstract}
Rheumatoid arthritis (RA) is the most common systemic autoimmune disease characterized by articular and extra-articular manifestations involving cardiovascular (CV) diseases. RA increases the CV mortality by up to $50 \%$ compared with the global population and CV disease is the leading cause of death in patients with RA. There is growing evidence that RA favors accelerated atherogenesis secondary to endothelial dysfunction (ED) that occurs early in the course of the disease. ED is a functional and reversible alteration of endothelial cells, leading to a shift of the actions of the endothelium towards reduced vasodilation, proinflammatory state, proliferative and prothrombotic properties. The mechanistic links between RA and ED have not been fully explained, but growing evidence suggests a role for traditional CV factors, auto-antibodies, genetic factors, oxidative stress, inflammation and iatrogenic interventions such as glucocorticoids (GCs) use. GCs have been used in RA for several decades. Whilst their deleterious CV side effects were described in the 1950s, their effect on CV risk associated with inflammatory arthritis remains subject for debate. GC might induce negative effects on endothelial function, via a direct effect on endothelium or via increasing CV risk factors. Conversely, they might actually improve endothelial function by decreasing systemic and/or vascular inflammation. The present review summarizes the available data on the impact of GCs on endothelial function, both in normal and inflammatory conditions, with a special focus on RA patients.
\end{abstract}

Keywords: Glucocorticoids, Endothelial function, Rheumatoid arthritis

\section{Background}

Rheumatoid arthritis (RA) is the most common systemic autoimmune disease characterized by reduced life expectancy ranging between 3 and 18 years compared with the general population [1]. The relative increase in risk of myocardial infarction and stroke is $68 \%$ and $41 \%$, respectively [1]. The leading cause of excess mortality in patients with RA is cardiovascular disease (CV) triggered by accelerated atherogenesis [1]. The CV risk in RA is roughly twice that of the general population and was found to be comparable to the risk in diabetes [2]. Most of the evidence suggests that "traditional" risk factors account for only part of the excess $\mathrm{CV}$ risk [1]. Other mechanisms, probably specific to RA, or increased by $\mathrm{RA}$, such as high-grade inflammation, are likely to play a

\footnotetext{
* Correspondence: cdemouge@univ-fcomte.fr

${ }^{1}$ EA 4267 FDE, FHU INCREASE, Université Bourgogne Franche-Comté, F-25030 Besancon, France

Full list of author information is available at the end of the article
}

role. Many, if not all, of these risk factors appear to affect $\mathrm{CV}$ health through changes in the endothelium. Indeed, in a wide range of CV diseases endothelial activation and dysfunction precedes and initiates atherosclerosis [3]. Endothelial dysfunction has prognostic value for $\mathrm{CV}$ events and its correction is associated with reduced CV risk [3]. Evidence from clinical studies has shown that endothelial dysfunction (ED) is present in established RA [4] and is impaired by genetic factors, like the presence HLA-DRB1*04 shared epitope alleles [5].

A woman with severe RA was successfully treated with glucocorticoids (GCs) for the first time in 1948, yet the majority of patients still use GCs in combination with disease-modifying antirheumatic drugs (DMARDs), and exceptionally alone, despite significant evolution in the treatment of RA. The link between $\mathrm{GC}$ and $\mathrm{CV}$ disease has been known since the 1950s when Adlersberg et al. demonstrated that the effect of cortisone on lipids was 
involved in premature development of atherosclerosis [6]. Since then, evidence obtained from the global population has shown that therapeutic doses of oral GC ( $\geq 7.5 \mathrm{mg} /$ day) are associated with increased CV disease and all-cause mortality [7].

GCs are responsible for insulin resistance, modification of the lipid profile and hypertension [8]. However, the effects of GCs on CV risk in inflammatory disease seem more complex. While GCs might increase $\mathrm{CV}$ risk by increasing $\mathrm{CV}$ risk factors, it might also reduce $\mathrm{CV}$ risk by decreasing the systemic and/or vascular inflammation. In giant cell arteritis, which is a large-vessel systemic vasculitis associated with high inflammatory burden, endothelial function was found to be impaired in individuals with active disease. Nevertheless, corticosteroids improved the endothelial function following suppression of the inflammation [9].

The effects of GCs on CV risk in RA have been addressed in recent reviews $[10,11]$ and have yielded variable results. GCs were found to increase $\mathrm{CV}$ and/or mortality risk, particularly with increasing doses $[10,11]$, or to have no effect or an uncertain effect [12]. As preserving endothelial function appears to be a major goal in mitigating $\mathrm{CV}$ risk in RA [4], the aim of the present review is to provide the available data on the effects of GCs on endothelial function, with a special focus on RA.

\section{Normal endothelial function}

The endothelium is a monocellular layer that plays a role as a physical barrier, being the interface between the blood and the vessel wall. However, the endothelium is not just a static tissue but also a crucial homeostatic organ for the regulation of vascular tone and structure. It senses mechanical stimuli, such as pressure and shear stress, and chemical stimuli, such as hormones and locally secreted vasoactive substances [3]. In response to these stimuli the endothelium releases factors that regulate vasomotor function, inflammatory processes, cell growth, and hemostasis. Since the importance of endothelium was first recognized by its capacity to release factors that modulate vascular tone [3], these factors are classically classified as endothelium-derived relaxing factors (EDRF) including nitric oxide (NO), prostacyclin $\left(\mathrm{PGI}_{2}\right)$ and endothelium-derived hyperpolarizing factor (EDHF), and endothelium-derived contracting factors (EDCF) including angiotensin-II, endothelin-1 and vasoconstrictor prostanoids.

\section{Vascular expression of GC receptors}

The synthetic GCs used in RA are agonists of glucocorticoid receptors (GR) and to a lesser extent of mineralocorticoid receptors (MR), which are both members of the nuclear receptor superfamily of ligand-activated transcription factors [13]. The main GR responsible for the therapeutic effects of GC is GR $\alpha$ which is expressed throughout the body, whereas MR is expressed in relatively few tissues [14]. Thus, the cellular response to GCs depends on whether the tissue expresses MR and/or GR. In the vascular system, GR and MR are expressed by intact arteries, cultured vascular smooth muscle cells (VSMC), and endothelial cells [8]. Thus, the conditions exist for a direct modulation of endothelial function by GCs.

\section{Endothelial dysfunction in RA}

Endothelial dysfunction (ED) is a widely used term to describe any form of abnormal functional and reversible alteration of endothelial cells, leading to an abnormal or inappropriate response to physiological stimuli and to a shift of the actions of the endothelium toward reduced vasodilation, proinflammatory state, and proliferative and prothrombotic properties [3, 15]. ED is an important early event in the pathogenesis of atherosclerosis, contributing to plaque initiation and progression [15]. The role of ED as the sine qua non condition for atherosclerosis development makes it an early indicator of disease at a stage that may allow for effective risk factor modification or pharmacologic intervention prior to the development of atherosclerosis.

Many techniques are available for assessing endothelial function in humans [16]. The most commonly used is the non-invasive method called flow-mediated dilation (FMD), which evaluates macrovascular endothelial function. FMD relies on the measurement by ultrasound of the vasodilatory response of the brachial artery to postischemic hyperemia. The limitations of this method are that it is a technically demanding technique and the duration of ischemia, which is variable. Microvascular endothelial function can be measured by invasive methods such as the forearm blood flow (FBF) technique, or noninvasive techniques such as laser Doppler skin flowmetry or digital pulse amplitude tonometry (PAT), but this new method need to be validated. The limitation of the FBF is its invasive nature and its duration.

ED in patients with RA was first described in 2002 [17]. This study reported the impairment in the brachial artery responsiveness to acetylcholine, assessed by FBF in patients with early disease. Since then, numerous publications have confirmed the presence of ED in RA $[4,16]$. ED was described both in the macrovasculature and in the microvasculature [18] in early RA [19] and in wellestablished disease [20] in patients with low [21] or high disease activity [22]. ED is present in patients with established RA, who in most cases do not have classic cardiovascular risk factors [6]. Thus, a role of inflammation in the development of ED is highly suspected but the channels through which rheumatic inflammation leads to ED are not completely clear. Data about endothelial mechanisms involved in ED have been provided by studies 
on animal models of RA. As reported in a recent review [23], RA-associated ED is secondary to decreased NO availability, decreased endothelial NOS expression/activity, uncoupling of endothelial NOS, increased arginase activity, excess of superoxide anion production, impaired EDHF production, increased synthesis of prostanoids and increased angiotensin II production.

\section{Direct effects of GCs on endothelial cells and function}

Evidence from in vitro and ex vivo models suggests that GCs are able to directly modulate endothelial function. However, their effects seem different depending on whether they are used in healthy conditions or in conditions associated with inflammation.

\section{Effects of GCs on endothelial function in the physiological condition}

GC treatment in animals leads to impaired endothelial function [24, 25]. As regards the mechanisms involved (Fig. 1), decreased vascular availability in NO, the major mediator of endothelial function produced by the vascular endothelial NO synthase (eNOS), has been demonstrated [25], which is secondary to decreased eNOS activity [26], eNOS expression [25], eNOS gene transcription [24], increased degradation of eNOS mRNA [27], decreased eNOS protein stability [24], inhibition of calcium mobilization in endothelial cells [26] or reduction of tetrahydrobiopterin levels, a cofactor required for eNOS enzyme activity [28]. Besides decreasing eNOS activity/expression, GCs have beem found to reduce vascular NO bioavailability by increasing reactive oxygen species (ROS) production. Exposure of cultured endothelial cells to dexamethasone increases ROS production by $\mathrm{NAD}(\mathrm{P}) \mathrm{H}$ oxidase and xanthine oxidase, decreases NO production and increases the production of the cytotoxic peroxynitrites $\left(\mathrm{ONOO}^{-}\right)[24,29]$.

Other studies demonstrate that $\mathrm{NO}$ is not the sole EDRF modulated by GCs. In a model of rats treated with a GR agonist, the treatment blunted aortic prostacyclin production [30]. Regarding EDHF, in a rat model of prenatal dexamethasone exposure, $\mathrm{GC}$ was responsible for an imbalance between EDHF and EDCF production, to the detriment of EDHF in the aorta [31]. GCs are also responsible for increased sensibility to endotheliumderived vasoconstrictors, such as endothelin-1 [25, 32].

In light of the above data obtained from tissue culture studies or studies in experimental animals, one would expect GCs to hamper endothelial function in humans. Surprisingly, the few studies exploring the impact of GCs on endothelium-dependent vasodilation in humans did not fully confirm this assumption. In 30 patients receiving $2 \mathrm{mg} / \mathrm{kg} /$ day of prednisolone orally for 4 weeks, endothelial function assessed by FBF was unchanged by the treatment [33]. Likewise, acute variations in plasma
GC concentrations (after an intravenous (i.v.) bolus of hydrocortisone) did not impair endothelial function measured by FBF in healthy men [34]. In 16 healthy male volunteers, an acute dose of oral prednisolone (single $50 \mathrm{mg}$ dose) did not change the response to acetylcholine assessed by forearm venous occlusion plethysmography as compared to placebo [35]. Conversely, the response to hyperemia measured by FBF in GC-treated patients was decreased as compared to the response before GC therapy. The administration of vitamin $\mathrm{C}$ almost normalized the blood flood response. Another study also identified significant attenuation of acetylcholine-induced vasodilation after 5 days but not after 2 days of hydrocortisone treatment [36]. These results could imply that although GC can produce detrimental defects in endothelial function, these are exerted over a period of time rather than acutely. In this latter study, the authors emphasized that the mineralocorticoid effects of hydrocortisone that may lead to ED could have biased the interpretation of the data.

\section{Effects of GCs on endothelial function in conditions associated with inflammation}

The role of the GCs on endothelial function in inflammatory conditions seems different compared to physiological conditions (Fig. 2). Compelling evidence argues for a beneficial vascular effect of GCs in high-grade inflammation associated with septic shock and this effect is mediated by the activation of the endothelial GC receptor [37, 38]. Interestingly, these positive effects of GCs seem also present in conditions associated with low-grade systemic inflammation, such as atherosclerosis [8]. Atherosclerotic mice lacking the endothelial GC receptor exhibit more severe atherosclerotic lesions than control mice, indicating that the endothelial GC receptor is important for the inhibition of atherosclerotic progression [39]. In a model of atherosclerotic mice (APOE*3-Leiden.CETP mice), both transient and continuous corticosterone treatment decreased the total atherosclerotic lesion area [40]. Similar results were found after chronic administration of dexamethasone in a model of cholesterol-fed rabbits [41]. The mechanisms involved in the beneficial effects of GC on endothelial cells in inflammatory conditions are likely due to a decrease in endothelial expression of cytokines (IL-6, IL-8), G-CSF, VEGF, endothelin-1, NFkB [42], arginase 2 [43] and COX-2 [44].

\section{Effects of GC on endothelial function in RA}

The forementioned animal data suggest that GCs might exert beneficial effects on endothelial function in a disease with a high level of inflammation, such as RA.

We performed a review of the literature (Fig. 3) using the Pubmed database with the following keywords: "rheumatoid arthritis" AND "endothelial function" AND 


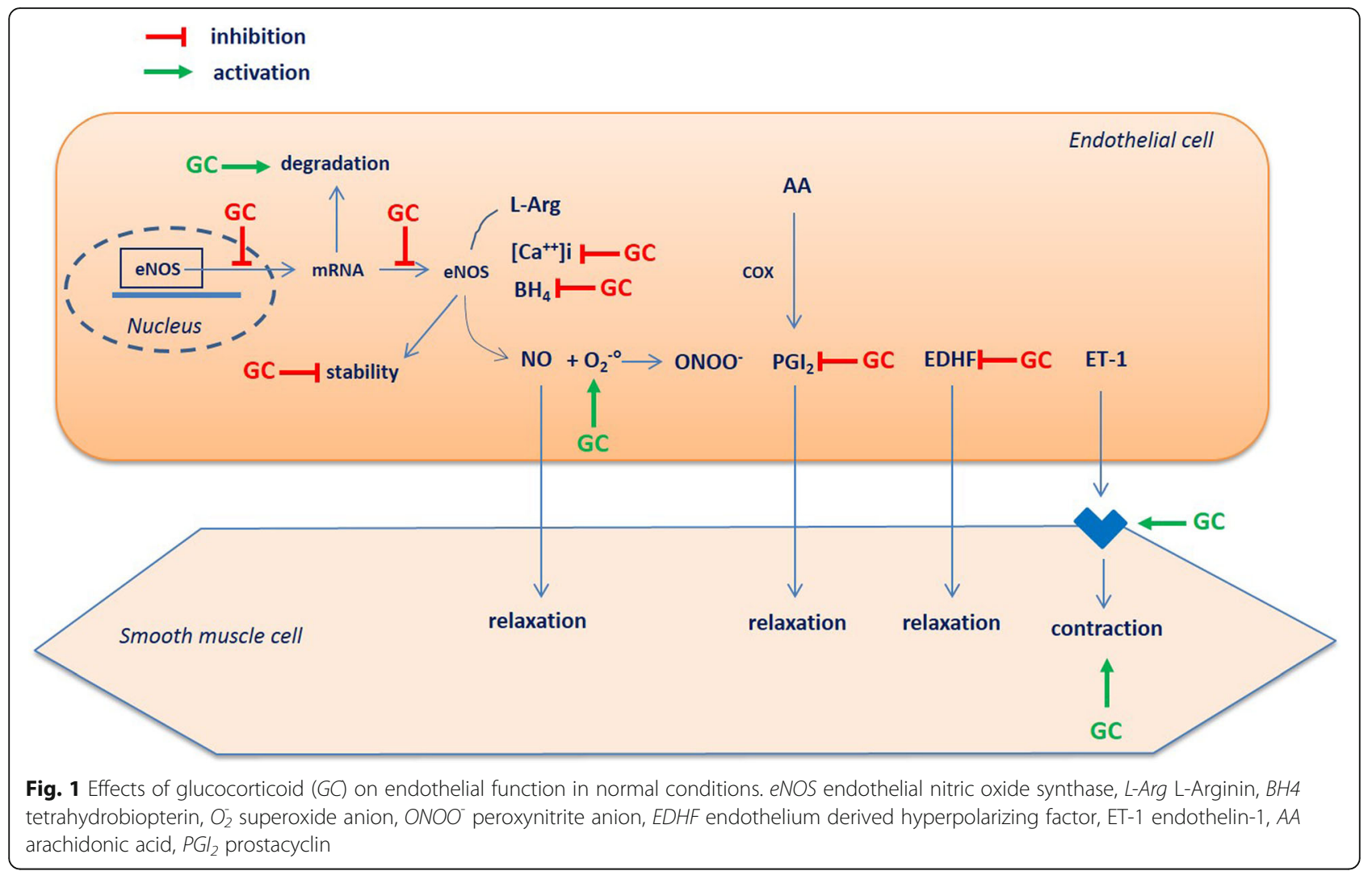

"treatment". We completed with a hand search. The search was restricted to studies in English and on humans older than 18 years. We identified 238 studies and 35 were selected after reading the titles: finally, after examination 5 studies were relevant for analysis (Table 1).

In a first study [45], 67 patients with early active RA were recruited (at the time of prescription of the first DMARD). Among them 34 patients received $7.5 \mathrm{mg} /$ day of prednisolone in addition to the DMARD and 33 received only the DMARD. In the group treated with prednisolone + DMARDs, only 13 patients were exclusively treated without treatment change over 5 years. After 5 years of treatment, endothelial function was measured by FMD of the brachial artery and atherosclerotic plaques were attested by ultrasonography. There was no difference in FMD and atherosclerotic plaques

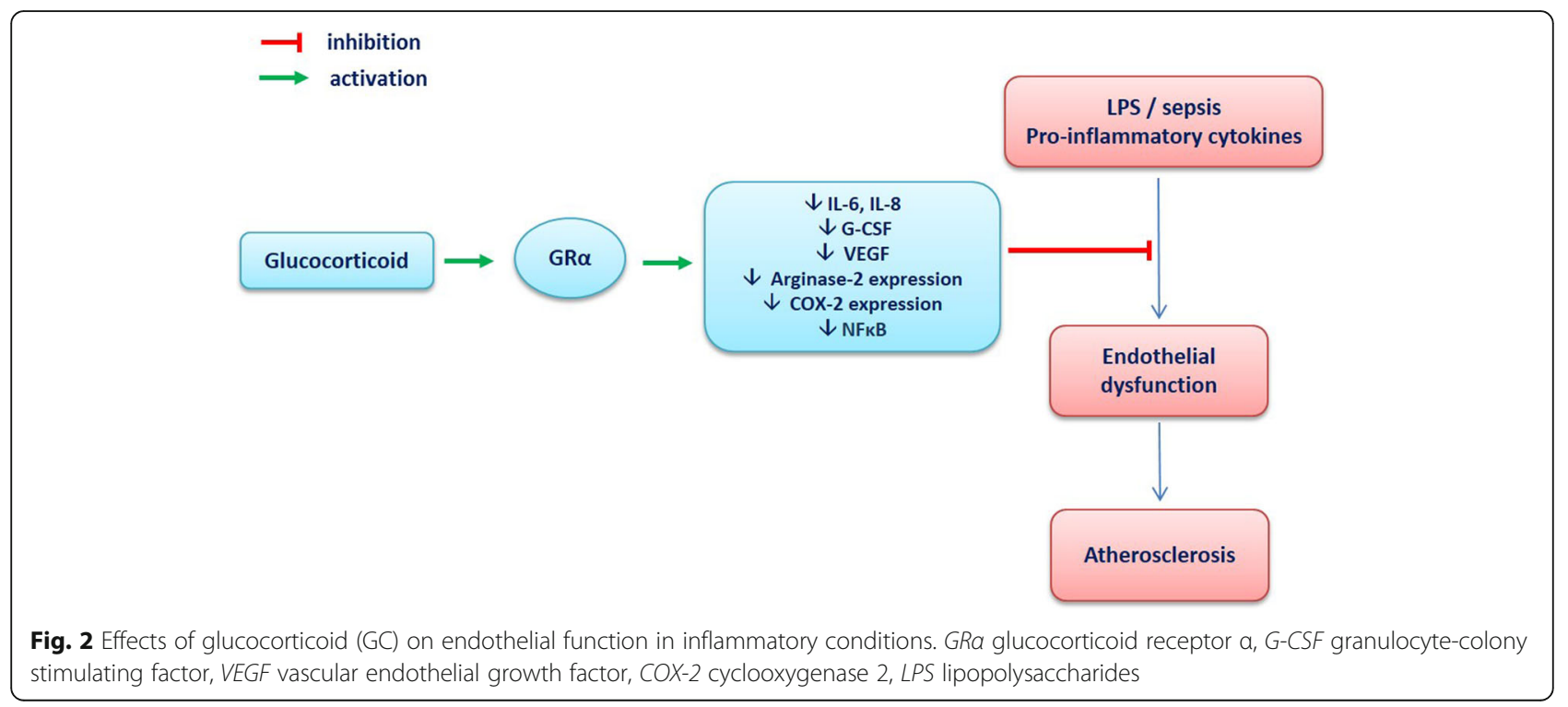


Table 1 Effects of GCs on endothelial function in RA

\begin{tabular}{|c|c|c|c|c|c|c|c|c|c|c|}
\hline & $\begin{array}{l}\text { Country of } \\
\text { the study }\end{array}$ & $\begin{array}{l}\text { Number of } \\
\text { patients }\end{array}$ & $\begin{array}{l}\text { Disease } \\
\text { duration } \\
\text { (years) }\end{array}$ & $\begin{array}{l}\text { Disease } \\
\text { activity } \\
\text { (DAS 28) }\end{array}$ & Treatment & $\begin{array}{l}\mathrm{GC} \text { treatment } \\
\text { duration }\end{array}$ & Control group & $\begin{array}{l}\text { Evaluation } \\
\text { criteria }\end{array}$ & Effect on endothelial function & $\begin{array}{l}\text { Newcastle- } \\
\text { Ottawa scale }\end{array}$ \\
\hline Hafström et al. [45] & Sweden & 13 & $<2$ & $3.0 \pm 1.3$ & $\begin{array}{l}\text { Prednisolone } 7.5 \text { mg/day } \\
\text { (p.o.) + DMARD }\end{array}$ & 5 years & DMARD alone & FMD & $3.44 \% \pm 2.08$ vs $3.74 \% \pm 2.9$ (NS) & 8 \\
\hline Ikonomidis et al. [46] & Greece & 19 & 10 & $5.3 \pm 1.1$ & $\begin{array}{l}\text { Prednisolone upper dose } \\
5 \mathrm{mg} / \text { day (p.o.) + DMARD }\end{array}$ & 30 days & Compared to baseline & FMD & $5.0 \% \pm 1.9$ vs $4.3 \% \pm 1.6$ (NS) & 9 \\
\hline Foster et al. [47] & England & 3 & 10.7 & - & $\begin{array}{l}\text { Methylprednisolone } \\
500 \text { mg (i.v.) }\end{array}$ & Single dose & Compared to baseline & FMD & $3.3 \%$ vs $3.1 \%$ (NS) & 4 \\
\hline Veselinovic et al. [48] & Serbia & 52 & 5.72 & $\begin{array}{l}3.69 \pm \\
0.84\end{array}$ & $\begin{array}{l}\text { Prednisolone } 7.5 \text { mg/day } \\
\text { (p.o.) + DMARD }\end{array}$ & $\begin{array}{l}\text { At least } \\
1 \text { year }\end{array}$ & RA patients without GC & FMD & $\begin{array}{l}9.16 \% \pm 7.03 \text { vs } 12.6 \% \pm 5.49 \\
P=0.005\end{array}$ & 7 \\
\hline Radhakutty et al. [49] & Australia & 18 & - & - & $\begin{array}{l}\text { Prednisolone } 6 \text { mg/day } \\
\text { (p.o.) }\end{array}$ & 7 days & $\begin{array}{l}\text { RA patients taking } \\
\text { prednisolone for } 6 \text { months } \\
\text { ( } 4-10 \mathrm{mg} / \text { day })\end{array}$ & PAT & No effect & 7 \\
\hline
\end{tabular}

GC glucocorticoid, RA rheumatoid arthritis, DAS28 disease activity score in 28 joints, DMARD disease-modifying antirheumatic drug, i.v. intravenous, p.o. orally, FMD flow-mediated dilation, FBF forearm blood flow, PAT peripheral arterial tonometry, NS not significant 


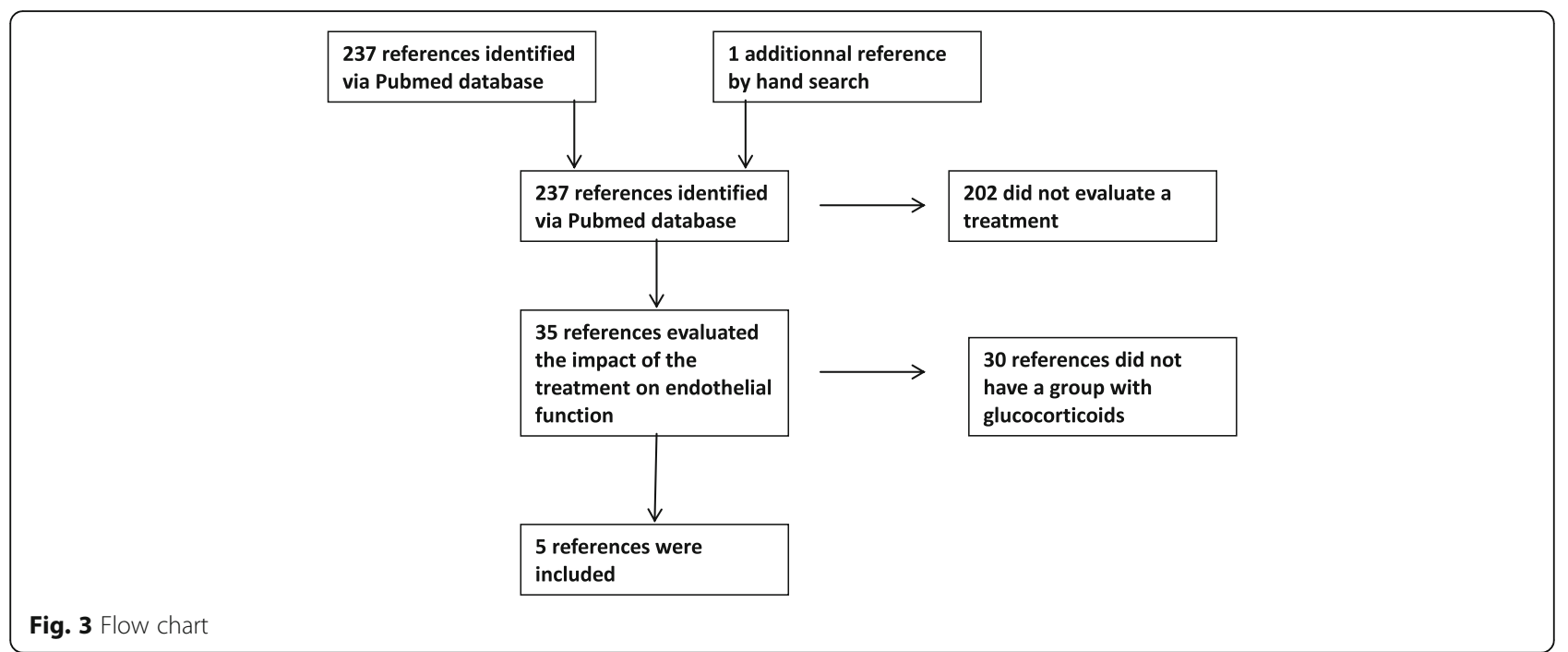

between the "DMARD alone" compared to the "DMARD + prednisolone" group. However, the DMARD + prednisolone group had hypertension and hypercholesterolemia more frequently compared to the DMARD alone group. The authors concluded that a low dose of GCs did not influence endothelial function and atherosclerosis in patients with RA. The major limitation of this study was the use of a DMARD that might exert is own effect on endothelial function.

Ikonomidis et al. [46] compared the effect of anakinra (an IL-1 receptor antagonist) on FMD of the brachial artery to treatment with a non-biologic DMARD (methotrexate, leflunomide or hydroxychloroquine) and to an upper dose of $5 \mathrm{mg} /$ day of prednisolone over 30 days. While patients treated with anakinra exhibited significantly improved FMD, patients treated with prednisolone had lower FMD than control subjects both before and after treatment $(P<0.05)$, but without improvement of FMD after the treatment. The main limitation was that this study was not designed to evaluate the effects of GCs on endothelial function. The dose of prednisolone was unclear and the group size was small (19 patients).

Forster et al. [47] investigated the impact of GCs on endothelial function of the macrocirculation (assessed by FMD) and the microcirculation (assessed by FBF) in patients (mean age 58.5 years; disease duration 10.7 years) with chronic RA. In this study, a subgroup of 29 patients required an additional antirheumatic treatment (antiTNF $\alpha$ or methotrexate or an i.v. bolus of $500 \mathrm{mg}$ methylprednisolone). In this subgroup, endothelial function was measured before the beginning of the new treatment, and 2 and 4 weeks later. Endothelial function (micro and macro) was not modified by GC treatment. Thus, infusion of a high dose of methylprednisone did not worsen endothelial function (but did not improve it) after 4 weeks. The limitations were the lack of history on the patients with RA and the possible co-prescription of methotrexate or anti-TNF $\alpha$ as a confounding factor.

Veselinovic et al. [48] investigated the correlation between intima-media thickness and FMD in 52 patients (mean age 52.46 years, disease duration 5.72 years) with RA treated with one or two DMARDs (methotrexate \pm hydroxychloroquine). Among these patients, 33 (63\%) were treated with a low dose of corticosteroids $(7.5 \mathrm{mg} /$ day of prednisone) continuously for a minimum of 1 year. FMD was significantly lower in RA as compared to controls $(P=0.005)$. Patients with RA taking low doses of GCs had significantly enhanced FMD compared to those who did not use corticosteroids. The main limitation of this study was the use of a non-biologic DMARD by every patient.

Very recently, Radhakutty et al. [49] aimed at comparing acute vs chronic treatment with GCs on post-prandial endothelial function in patients with RA. Microvascular endothelial function (assessed by PAT) was measured before and after a standardized meal, in 18 patients with RA (mean age 66 years), who were taking continuous oral prednisolone $4-10 \mathrm{mg} /$ day for at least 6 months (chronic treatment) or 18 patients with RA (mean age 64 years) taking a 7-day course of oral prednisolone $6 \mathrm{mg} /$ day (acute treatment). The results showed that there was no difference in post-prandial endothelial function between chronic and acute GC treatment. The main study limitations were the lack of information on RA duration or severity, the use of DMARDs in some patients, the small group size and the lack of a control group.

\section{Conclusion}

Despite their well-documented adverse effects, GCs are still included in the American College of Rheumatology (ACR)/European League Against Rheumtism (EULAR) recommendations for the management of RA. Given the 
seminal role of $\mathrm{ED}$ as the precursor of $\mathrm{CV}$ diseases, it is important to determine and understand whether GCs are likely to influence endothelial function in patients with RA. Data from experimental models highlight the Janus face of GCs: they can exert deleterious effects on endothelial function when applied in "normal" cells/animals but they also seem protective under inflammatory conditions. In patients with RA, data are scarce and controversial. While most studies showed no deterioration of endothelial function after a treatment with a low dose or a bolus of GCs, one study reported improvement in endothelial function after 1 year of treatment with a low dose of a GC [48]. The effects of GCs are likely independent on disease duration [49]. Thus, despite the classical assumption that GCs are responsible for deterioration in endothelial function, no available data in the literature demonstrate such an effect in RA. However, the present review pointed out the great heterogeneity in the design of available studies (various stages of RA disease, various dosages of GCs or treatment durations) which makes the results of these studies inconclusive. Therefore, there is an urgent need to perform clinical trials specifically designed to define the best GC strategy to prevent $\mathrm{CV}$ risk in RA.

\begin{abstract}
Abbreviations
COX: Cyclooxygenase; CV: Cardiovascular; DMARDs: Disease-modifying antirheumatic drugs; ED: Endothelial dysfunction; EDCF: Endothelium-derived contracting factors; EDHF: Endothelium-derived hyperpolarizing factor; EDRF: Endothelium-derived relaxing factor; eNOS: Endothelial nitric oxide synthase; FBF: Forearm blood flow; FMD: Flow mediated dilation; GCs: Glucocorticoids; G-CSF: Granulocyte-colony stimulating factor: GR: Glucocorticoid receptor; IL: Interleukin; i.v.: Intravenous(ly); MR: Mineralocorticoid receptor; mRNA: Messenger RNA; NADPH: Reduced nicotinamide adenine dinucleotide phosphate; NFkB: Nuclear factor-kappa B; NO: Nitric oxide; NOS: Nitric oxide synthase; PAT: Pulse amplitude tonometry; $\mathrm{PG}_{2}$ : Prostacyclin, RA, rheumatoid arthritis; ROS: Reactive oxygen species; TNFa: Tumor necrosis factor a; VEGF: Vascular endothelial growth factor
\end{abstract}

\section{Acknowledgements}

Not applicable.

Funding

None.

\section{Availability of data and materials}

The dataset supporting the conclusions of this article is included within the article.

\section{Authors' contributions}

FV and CD designed the review and drafted the manuscript. CP, KMG and DW participated in the design of the review and helped with drafting the manuscript. All authors read and approved the final manuscript.

\section{Authors' information}

Not applicable.

\section{Competing interests}

The authors declare that they have no competing interests.

\section{Consent for publication}

Not applicable.

Ethics approval and consent to participate Not applicable.

\section{Author details}

${ }^{1}$ EA 4267 FDE, FHU INCREASE, Université Bourgogne Franche-Comté, F-25030 Besancon, France. ${ }^{2}$ Service de Rhumatologie, CHRU Besançon, F-25030 Besançon, France. ${ }^{3}$ EA 4266, Université Bourgogne Franche-Comté, F-25030 Besancon, France.

Published online: 05 November 2016

\section{References}

1. Giles JT. Cardiovascular diseases in rheumatoid arthritis: current perspectives on assessing and mitigating risk in clinical practice. Best Pract Res Clin Rheumatol. 2015;29:597-613.

2. van Halm VP, Peters MJ, Voskuyl AE, Boers M, Lems WF, Visser M, Stehouwer CD, Spijkerman AM, Dekker JM, Nijpels G, Heine RJ, Bouter LM, Smulders YM, Dijkmans BA, Nurmohamed MT. Rheumatoid arthritis versus diabetes as a risk factor for cardiovascular disease: a cross-sectional study, the CARRE Investigation. Ann Rheum Dis. 2009;68:1395-400.

3. Daiber A, Steven S, Weber A, Shuvaev W, Muzykantov VR, Laher I, Li H, Lamas S, Münzel T. Targeting vascular (endothelial) dysfunction. Br J Pharmacol. 2016. doi:10.1111/bph.13517.

4. Di Minno MN, Ambrosino P, Lupoli R, Di Minno A, Tasso M, Peluso R, Tremoli E. Clinical assessment of endothelial function in patients with rheumatoid arthritis: a meta-analysis of literature studies. Eur J Intern Med. 2015;26:835-42.

5. Gonzalez-Juanatey C, Testa A, Garcia-Castelo A, Garcia-Porrua C, Llorca J, Vidan J, Hajeer AH, Ollier WE, Mattey DL, Gonzalez-Gay MA. HLA-DRB1 status affects endothelial function in treated patients with rheumatoid arthritis. Am J Med. 2003;114:647-52.

6. Adlersberg D, Schaefer L, Drachman SR. Development of hypercholesteremia during cortisone and ACTH therapy. JAMA. 1950;144:909-14.

7. Souverein PC, Berard A, Van Staa TP, Cooper C, Egberts AC, Leufkens HG, Walker BR. Use of oral glucocorticoids and risk of cardiovascular and cerebrovascular disease in a population based case-control study. Heart. 2004;90:859-65.

8. Walker BR. Glucocorticoids and cardiovascular disease. Eur J Endocrinol. 2007;157:545-59.

9. Gonzalez-Juanatey C, Llorca J, Garcia-Porrua C, Sanchez-Andrade A, Martín J, Gonzalez-Gay MA. Steroid therapy improves endothelial function in patients with biopsy-proven giant cell arteritis. J Rheumatol. 2006;33(1):74-8.

10. Listing J, Kekow J, Manger B, Burmester GR, Pattloch D, Zink A, Strangfeld A. Mortality in rheumatoid arthritis: the impact of disease activity, treatment with glucocorticoids, TNFa inhibitors and rituximab. Ann Rheum Dis. 2015;74:415-21.

11. del Rincón I, Battafarano DF, Restrepo JF, Erikson JM, Escalante A. Glucocorticoid dose thresholds associated with all-cause and cardiovascular mortality in rheumatoid arthritis. Arthritis Rheumatol. 2014;66:264-72.

12. Ajeganova S, Svensson B, Hafström I, BARFOT Study Group. Low-dose prednisolone treatment of early rheumatoid arthritis and late cardiovascular outcome and survival: 10-year follow-up of a 2-year randomised trial. BMJ Open. 2014;4:e004259.

13. Alexander SPH, Mathie A, Peters JA. Guide to receptors and channels (GRAC), 3rd edition (2008 revision). Br J Pharmacol. 2008;153:S1-S209.

14. Arriza JL, Weinberger C, Cerelli G. Cloning of human mineralocorticoid receptor complementary DNA; structural and functional kinship with the glucocorticoid receptor. Science. 1987;237:268-75.

15. Mudau M, Genis A, Lochner A, Strijdom H. Endothelial dysfunction: the early predictor of atherosclerosis. Cardiovasc J Afr. 2012;16:222-31.

16. Steyers 3rd CM, Miller Jr FJ. Endothelial dysfunction in chronic inflammatory diseases. Int J Mol Sci. 2014;15:11324-49.

17. Bergholm R, Leirisalo-Repo M, Vehkavaara S, Mäkimattila S, Taskinen MR, Yki-Järvinen H. Impaired responsiveness to NO in newly diagnosed patients with rheumatoid arthritis. Arterioscler Thromb Vasc Biol. 2002;22:1637-41.

18. Sandoo A, Carroll D, Metsios GS, Kitas GD, Veldhuijzen van Zanten JJ. The association between microvascular and macrovascular endothelial function in patients with rheumatoid arthritis: a cross-sectional study. Arthritis Res Ther. 2011;13(3):R99.

19. Chatterjee Adhikari M, Guin A, Chakraborty S, Sinhamahapatra P, Ghosh A. Subclinical atherosclerosis and endothelial dysfunction in patients with early rheumatoid arthritis as evidenced by measurement of carotid intima-media thickness and flow-mediated vasodilatation: an observational study. Semin Arthritis Rheum. 2012;41:669-75. 
20. Kerekes G, Szekanecz Z, Der H, Sandor Z, Lakos G, Muszbek L, Csipö I, Sipka S, Seres I, Paragh G, Kappelmayer J, Szomják E, Veres K, Szegedi G, Shoenfeld Y, Soltész P. Endothelial dysfunction and atherosclerosis in rheumatoid arthritis: A multiparametric analysis using imaging techniques and laboratory markers of inflammation and autoimmunity. J Rheumatol. 2008;35:398-406.

21. Vaudo $G$. Endothelial dysfunction in young patients with rheumatoid arthritis and low disease activity. Ann Rheum Dis. 2004;63:31-5.

22. de Groot L, Jager NA, Westra J, Smit AJ, Kallenberg CG, Posthumus MD, Bijl M. Does reduction of disease activity improve early markers of cardiovascular disease in newly diagnosed rheumatoid arthritis patients? Rheumatology. 2015;54:1257-61.

23. Totoson P, Maguin-Gaté K, Prati C, Wendling D, Demougeot C. Mechanisms of endothelial dysfunction in rheumatoid arthritis: lessons from animal studies. Arthritis Res Ther. 2014;16:202.

24. Schäfer SC, Wallerath T, Closs El, Schmidt C, Schwarz PM, Förstermann U, Lehr HA. Dexamethasone suppresses eNOS and CAT-1 and induces oxidative stress in mouse resistance arterioles. Am J Physiol Heart Circ Physiol. 2005;288:H436-444.

25. Ramzy D, Tumiati LC, Tepperman E, Sheshgiri R, Jackman J, Badiwala M, Rao V. Dual immunosuppression enhances vasomotor injury: interactive effect between endothelin-1 and nitric oxide bioavailability. J Thorac Cardiovasc Surg. 2008;135:938-44

26. Rogers KM, Bonar CA, Estrella JL, Yang S. Inhibitory effect of glucocorticoid on coronary artery endothelial function. Am J Physiol Heart Circ Physiol. 2002;283:1922-8

27. Liu Y, Mladinov D, Pietrusz JL, Usa K, Liang M. Glucocorticoid response elements and $11 \beta$-hydroxysteroid dehydrogenases in the regulation of endothelial nitric oxide synthase expression. Cardiovasc Res. 2009;81:140-7.

28. Dorrance AM, Mack EA, Webb RC. Glucocorticoids decrease GTP cyclohydrolase and tetrahydrobiopterin-dependent vasorelaxation through glucocorticoid receptors. J Cardiovasc Pharmacol. 2004;43:8-13.

29. Iuchi T, Akaike M, Mitsui T, Ohshima Y, Shintani Y, Azuma H, Matsumoto T. Glucocorticoid excess induces superoxide production in vascular endothelial cells and elicits vascular endothelial dysfunction. Circ Res. 2003;92:81-7.

30. Grunfeld JP, Eloy L, Araujo A, Russo-Marie F. Effects of gluco and antiglucocorticoids on renal and aortic prostaglandin synthesis. Am J Physiol. 1986;251:F810-6.

31. Sheen JM, Yu HR, Tiao MM, Chen CC, Huang LT, Chang HY, Tain YL. Prenatal dexamethasone-induced programmed hypertension and renal programming. Life Sci. 2015;132:41-8.

32. Lee JH, Zhang J, Massmann GA, Figueroa JP. Antenatal betamethasone increases vascular reactivity to endothelin-1 by upregulation of CD38/ CADPR signaling. J Dev Orig Health Dis. 2014;5:56-62.

33. Yadav A, Jahan A, Yadav TP, Sachdev N, Chitkara A, Asare R. Effect of glucocorticoids on serum lipid profile and endothelial function and arterial wall mechanics. Indian J Pediatr. 2013:80:1007-14.

34. Dover AR, Hadoke PW, Walker BR, Newby DE. Acute effects of glucocorticoids on endothelial fibrinolytic and vasodilator function in humans. J Cardiovasc Pharmacol. 2007:50:321-6.

35. Farquharson CA, Struthers AD. Aldosterone induces acute endothelia dysfunction in vivo in humans: evidence for an aldosterone-induced vasculopathy. Clin Sci (Lond). 2002;103:425-31.

36. Mangos GJ, Walker BR, Kelly JJ, Lawson JA, Webb DJ, Whitworth JA. Cortisol inhibits cholinergic vasodilation in the human forearm. Am J Hypertens. 2000;13:1155-60.

37. Goodwin JE, Feng Y, Velazquez H, Sessa WC. Endothelial glucocorticoid receptor is required for protection against sepsis. Proc Natl Acad Sci USA. 2013;110:306-11.

38. Goodwin JE, Feng Y, Velazquez H, Zhou H, Sessa WC. Loss of the endothelial glucocorticoid receptor prevents the therapeutic protection afforded by dexamethasone after LPS. PLoS One. 2014;9:e108126.

39. Auvinen HE, Wang Y, Princen H, Romijn JA, Havekes LM, Smit JW, et al. Both transient and continuous corticosterone excess inhibit atherosclerotic plaque formation in APOE*3-Leiden.CETP mice. PLoS One. 2013;8:e63882.

40. Asai K, Funaki C, Hayashi T, Yamada K, Naito M, Kuzuya M, Yoshida F, Yoshimine N, Kuzuya F. Dexamethasone-induced suppression of aortic atherosclerosis in cholesterol-fed rabbits. Possible Mechanisms Arterioscler Thromb. 1993;13:892-9.

41. Ribichini F, Joner M, Ferrero V, Finn AV, Crimins J, Nakazawa G, Acampado E, Kolodgie FD, Vassanelli C, Virmani R. Effects of oral prednisone after stenting in a rabbit model of established atherosclerosis. J Am Coll Cardiol. 2007:50:176-85.

42. Edgar AR, Judith PY, Elisa DS, Rafael CR. Glucocorticoids and estrogens modulate the NF-KB pathway differently in the micro- and microvasculature Med Hypotheses. 2013;81:1078-82.

43. Klasen S, Hammermann R, Fuhrmann M, Lindemann D, Beck KF, Pfeilschifter J, Racké K. Glucocorticoids inhibit lipopolysaccharide-induced up-regulation of arginase in rat alveolar macrophages. Br J Pharmacol. 2001;132:1349-57.

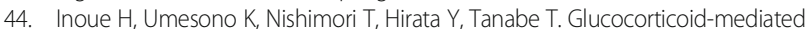
suppression of the promoter activity of the cyclooxygenase-2 gene is modulated by expression of its receptor in vascular endothelial cells. Biochem Biophys Res Commun. 1999;254:292-8.

45. Hafström I, Rohani M, Deneberg S, Wörnert M, Jogestrand T, Frostegård J, Effects of low-dose prednisolone on endothelial function, atherosclerosis, and traditional risk factors for atherosclerosis in patients with rheumatoid arthritis-a randomized study. J Rheumatol. 2007;34:1810-6.

46. Ikonomidis I, Lekakis JP, Nikolaou M, Paraskevaidis I, Andreadou I, Kaplanoglou T, Katsimbri P, Skarantavos G, Soucacos PN, Kremastinos DT. Inhibition of interleukin-1 by anakinra improves vascular and left ventricular function in patients with rheumatoid arthritis. Circulation. 2008;117:2662-9.

47. Foster W, Carruthers D, Lip GY, Blann AD. Inflammation and microvascular and macrovascular endothelial dysfunction in rheumatoid arthritis: effect of treatment. J Rheumatol. 2010;37:711-6.

48. Veselinovic MV, Zivkovic VI, Toncev S, Tasic N, Bogdanovic V, Djuric DM, Jakovljevic VL. Carotid artery intima-media thickness and brachial artery flow-mediated vasodilatation in patients with rheumatoid arthritis. Vasa. 2012:41:343-51.

49. Radhakutty A, Mangelsdorf BL, Drake SM, Samocha-Bonet D, Jenkins AB, Heilbronn LK, Smith MD, Thompson CH, Burt MG. Effect of acute and chronic glucocorticoid therapy on insulin sensitivity and postprandial vascular function. Clin Endocrinol. 2016:84:501-8. 